\title{
Judging the best of Indian healthcare
}

\author{
Nominations have now closed, and judging has begun, for the first BMJ Awards India, which will \\ be presented on 20 September 2014 in New Delhi. Jeetha D'Silva reports
}

\author{
Jeetha D'Silva journalist, Mumbai
}

\begin{abstract}
"We received an overwhelming number of nominations," said Anand Ekambaram, managing director of BMJ India. More than 500 individuals and teams throughout India have been put forward. ${ }^{1}$

"The BMJ India Awards are a very prestigious recognition, and it is an honour to be among the nominees," said Sarman Singh, professor and head of the division of clinical microbiology and molecular medicine at the All India Institute of Medical Sciences in New Delhi. He thinks that the awards indicate the progress that Indian healthcare has made. "We have also seen an increase in the acceptance rate of research papers from India in leading medical publications across the world," he said.
\end{abstract}

\section{An easy test for leishmaniasis}

Singh had been nominated in the Innovation in Healthcare Technology category for developing a high quality and cost effective diagnostic test for visceral leishmaniasis, a neglected tropical disease that kills around 50000 people a year worldwide. $^{2}$

Current best practice for diagnosing leishmaniasis is microscopic detection of the parasite. However, taking samples from the lymph node, bone marrow, or spleen aspirate requires expertise and is potentially dangerous and so cannot be done everywhere. Singh's work forms the basis for simple blood tests now in use to detect antibodies produced after infection. ${ }^{3}$ The World Health Organization says that these tests, which cost about Rs 40 (£0.40; $€ 0.50 ; \$ 0.66$ ), are the best diagnostic tool for remote places. $^{2}$

\section{Join the virtual DOTS}

The BMJ India Awards will acknowledge doctors and healthcare organizations working in peripheral regions. "This can be a motivation for younger doctors to go and work in the community," said Sunny George, associate professor of pulmonology at the Institute of Chest Diseases, Government Medical College, Kozhikode, in Kerala.

George has been shortlisted for the Excellence in Preventive Health Award for his work on decentralising the medical management of multidrug resistant tuberculosis (MDR TB) through "virtual consultancy."

In the standard protocol of the government-run tuberculosis control programme, patients are given antituberculosis drugs under direct observation of the healthcare provider-that is, "directly observed treatment, short course" (DOTS). ${ }^{3}$ Kerala has only two "DOTS plus" centres, which can also test for drug susceptibility for the management of MDR TB. This means that many patients have to travel long distances.

"Asking patients with MDR TB to report to the government centre at regular intervals is illogical and poses a high risk of transmission to the community as most of these patients use public transport," explained George. To curtail the spread of the MDR TB bacilli in the community, George and his team set up a virtual consultancy in 2009. They trained doctors from peripheral towns to manage patients, while George and his team monitored treatment and follow-up remotely.

"The Kozhikode model has shown a success rate of $68.2 \%$, which is at par with the success of standard of care reported for drug resistant tuberculosis in the literature," he added. This project is now being considered for wider implementation at DOTS plus centres throughout the country, George said.

\section{Healthcare for remote tribes}

The Jawadhi Hills Health and Development Project, which has been shortlisted in the Primary Healthcare under Challenging Circumstances category, is another initiative that is striving to improve healthcare in remote regions. Three times a week Anuradha Rose, associate professor of community medicine at the Christian Medical College, Vellore in Tamil Nadu, makes the four hour trip to remote villages in the surrounding hills. Rose's project provides healthcare services to the tribal people of this region.

"CMC first started working in this region 30-40 years ago. Initially we did leprosy and TB work, but gradually the scope of services expanded to offer other primary health services," Rose told The BMJ. 
Since 2007, the project has been scaled up. "We started looking at health, socioeconomic development, and education," Rose said. The project team trained and recruited people from the community to improve health outcomes in the region. In the past five years, many of the health and development indicators for the region have improved, including infant and maternal mortality.

In July 2014, the team set up a primary healthcare centre in the region. CMC Vellore continues to run a mobile service to provide healthcare to more remote parts. "Through the BMJ Awards India I hope more people are inspired to start similar initiatives," said Rose.

\section{Stiff competition}

Singh, George, and Rose are among 142 nominees shortlisted in the first stage of judging. All the nominations were screened internally by the BMJ Awards India team. Although their entries were judged to highlight excellence in Indian medicine, the competition is stiff, and they may not reach the final shortlist.

Prashant Jha, head of clinical engagement at BMJ India, explained that each entry was judged on novelty, scalability, impact, and ability to improve healthcare in the Indian subcontinent. Shortlisted nominations will be reviewed further to select three finalists for each of the 10 awards to be announced on 5 September, with the winners of each category announced on 20 September 2014.

Finalists will be invited to make a presentation to a panel of doctors, academics, researchers, and public health champions, who will decide who wins. The judges, nominated by the BMJ India team, come from different parts of India and have been chosen for their record in clinical excellence, research, and policy (box). To promote objectivity, the nine judges will be split into groups of three, and no jury member will be part of a panel that is considering an entry from the same institution or who has an affiliation with the nominee.

BMJ's India editor, Anita Jain, said, "Our intention is to showcase knowledge, expertise, and practices that are helping to transform healthcare throughout rural as well as urban areas. Our judges will be looking for cutting edge achievements, ways in which challenges were overcome, and impact on health outcomes, with the expectation that these will serve as inspiration to the rest of the medical community in India and across the globe."

The overall winners will be announced at a lavish function before an invited audience of 500 of India's most senior doctors, healthcare professionals, healthcare industry executives, government officials, academics, and researchers, including all the shortlisted individuals and teams. Fiona Godlee, editor in chief of The BMJ, will present the awards, and Tim Brooks, chief executive of BMJ, will deliver the keynote address.

\section{First BMJ awards outside UK}

The awards categories include preventive health, innovation in healthcare technology, primary healthcare in challenging circumstances, research paper of the year, excellence in medical education, quality improvement in healthcare, healthcare campaigning or advocacy, surgical team of the year, and medical team of the year. The biotechnology publication BioSpectrum India said they "will not only provide a platform to enhance the existing relationship with the healthcare community but will also offer an opportunity to meet key influencers in the country." ${ }^{4}$

The UK has had an annual BMJ Awards since 2009 to recognise excellence in healthcare, but this is the first time that BMJ has run dedicated awards for another region. Ekambaram said, "India is home to extraordinary doctors and their teams, who have made tangible contributions to improving patient care and healthcare outcomes in arduous circumstances. We have seen this in 2011, when two winners at the BMJ Awards in the UK were from India."

He added that the BMJ Awards India will applaud stories of determination, vision, insight, and innovation in medicine throughout the country. He intends that this initiative will recognise the real heroes of healthcare in the country.

Competing interests: I have read and understood BMJ policy on declaration of interests and have no relevant interests to declare. Provenance and peer review: Commissioned; not externally peer reviewed.

Follow @BMJIndia on Twitter for all the latest news and use the hashtag \#BMJAwardsIndia

1 Hurley R. The "Oscars of medicine" are coming to New Delhi: who will you nominate as a hero of Indian healthcare? BMJ 2014:349.94540.

2 WHO. Fact sheet on visceral leishmaniasis/kala-azar. www.searo.who.int/entity/vector borne_tropical_diseases/data/FactSheetVL.pdf.

3 Singh S, Sivakumar R. Polypeptides for the diagnosis and therapy of leishmaniasis. PCT/IN03/00400. Expert Opinion on Therapeutic Patents 2005;15:1439-65.

4 First ever BMJ Awards India announced. BioSpectrum 2014 Jun 30. www. biospectrumindia.com/biospecindia/news/216818/first-bmj-awards-india-announced. 


\section{Confirmed judges}

Anoop Mishra, director and head, Department of Diabetes and Metabolic Diseases, Fortis Hospitals

Samiran Nundy, emeritus consultant, Surgical Gastroenterology and Liver Transplantation, Sir Ganga Ram Hospital, Delhi

Nata Menabde, WHO representative to India

Ashok Seth, chairman of Cardiology Council, Fortis Group of Hospitals

Payal Bansal, associate professor and head, Department of Medical Education and Technology and convener, $\mathrm{MCI}$ Regional Centre for Faculty Development, Maharashtra University of Health Sciences, Regional Centre, Pune

T V Devarajan, consultant, Apollo Hospitals, Chennai

Velu Nair, dean, Armed Forces Medical College, Pune

Himanshu Pandya, professor of medicine and convenor, MCI Nodal Centre for Faculty Development, Pramukhswami Medical College, Karamsad, Gujarat, India 